\title{
Conflation and Integration of Archived Geologic Maps and Associated Uncertainties
}

\author{
Tom Shoberg ${ }^{1}$ \\ ${ }^{1}$ U.S. Geologic Survey, Center of Excellence for Geospatial Information Science (CEGIS), USA \\ Correspondence: Tom Shoberg, U.S. Geologic Survey, Center of Excellence for Geospatial Information Science \\ (CEGIS), 1400 Independence Road, Rolla, MO, 65401, USA. E-mail: tshoberg@usgs.gov
}

Received: January 9, 2016

Accepted: January 31, 2016

Online Published: February 9, 2016

doi:10.5539/jgg.v8n1p28

URL: http://dx.doi.org/10.5539/jgg.v8n1p28

\begin{abstract}
Old, archived geologic maps are often available with little or no associated metadata. This creates special problems in terms of extracting their data to use with a modern database. This research focuses on some problems and uncertainties associated with conflating older geologic maps in regions where modern geologic maps are, as yet, non-existent as well as vertically integrating the conflated maps with layers of modern GIS data (in this case, The National Map of the U.S. Geological Survey). Ste. Genevieve County, Missouri was chosen as the test area. It is covered by six archived geologic maps constructed in the years between 1928 and 1994. Conflating these maps results in a map that is internally consistent with these six maps, is digitally integrated with hydrography, elevation and orthoimagery data, and has a $95 \%$ confidence interval useful for further data set integration.
\end{abstract}

Keywords: data integration, geologic maps, cartographic uncertainties

\section{Introduction}

While the push from paper to digital geologic maps has encouraged new mapping efforts among many state and federal mapping agencies, large areas of United States coverage are best thought of as a "patchwork quilt" of maps authored by different compilers, constructed at different times, with differing scales, and even using different stratigraphic units (Soller, Berg, \& Wahl, 2000). This implies that, at least for the foreseeable future, it will be necessary to rely on archived geologic maps for geological and societal interpretation for many areas of the United States. Indeed, a large number of geologic maps are stored (rather than formally archived) in geological surveys, university faculty file drawers, theses and dissertations in university libraries, engineering reports, and elsewhere (Hatcher, 2005) and, as a result, represent an underutilized, and occasionally unknown, resource.

These archived geologic maps may contain a wealth of information about a region, but due to losses during storage or in institutional knowledge, they often have little or no associated metadata. While accessing these maps has become considerably easier with online database constructions such as the National Geologic Map Database (NGMD) project of the United States Geological Survey (USGS) (Soller, Berg, \& Wahl, 2000; Soller \& Stamm, 2014), moving from a paper geologic map used by geologists to a digital on-line geologic map easily accessible to the general public introduces several challenges to a mapping institution (Wunderlich \& Hatcher, 2009). Further, considerable added value can be obtained by integrating these digital maps with other types of data on a modern GIS platform.

A general problem arises in the use of on-line digital geologic maps when accessed by individuals or agencies not familiar with their limitations. Geologic maps represent the interpretation of the surface and, to some extent, subsurface geology, generally based on limited geological and geophysical data observed or collected by the creator of the map at a given scale. Digital geologic maps, however, can be scaled down to a single point were an exact latitude and longitude is delivered along with a feature element (rock type, age, formation, etc.), that may imply an unwarranted certitude of bedrock knowledge. Three-dimensional digital geologic models add to these challenges by extending this problem to depth within Earth. For example, a digital geologic 3-D model can show a constrained aquifer at a depth of $100.35 \mathrm{~m}$ beneath a given surface location, but that precision may be far too great considering the uncertainties inherent in the model. 
This research looks at some of the problems and uncertainties associated with conflating archived geologic maps together (in regions where modern maps are, as yet, non-existent) as well as vertically integrating these maps with layers of modern GIS data (in this case, The National Map of the U.S. Geological Survey).

\section{Example Area}

Ste. Genevieve County, Missouri was chosen as the test area. It is covered, in part, by six archived geologic maps constructed in the years between 1928 and 1994. Conflating these maps result in a map that is internally consistent with these six maps and is digitally integrated with hydrography, elevation and orthoimagery data from The National Map.

The archived geologic maps to be combined cover all of Ste. Genevieve county and parts of St. Francois and Perry Counties, all in southeastern Missouri about 95 kilometers $(\mathrm{km})$ south of the city of St. Louis. The area of investigation is bounded by latitude $38.12^{\circ} \mathrm{N}$ on the north, longitude $89.75^{\circ} \mathrm{W}$ on the east, latitude $37.50^{\circ} \mathrm{N}$ on the south and longitude $90.50^{\circ} \mathrm{W}$ on the west, covering about $2000 \mathrm{~km}^{2}$ (Figure 1). This area includes a small section of the St. François Mountains in its southern extent, as well as the Avon igneous intrusions, and Hawn State Park.

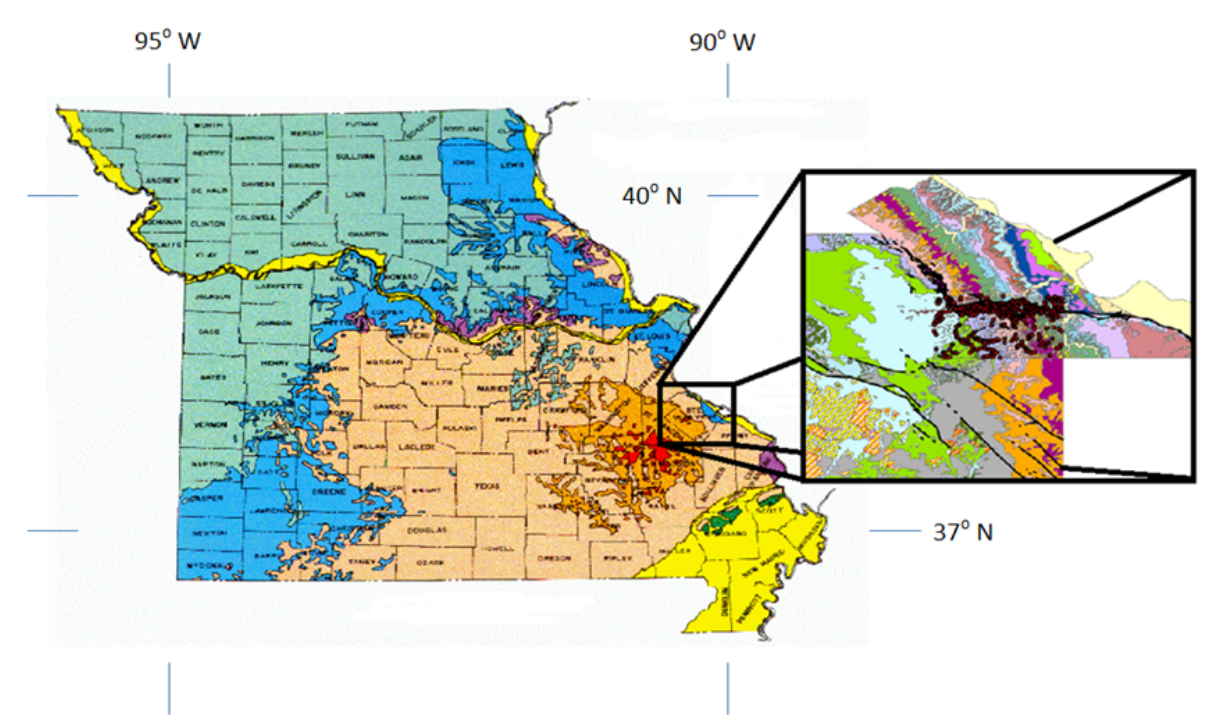

Figure 1. Location map of Missouri with inset box showing the example area

\section{Data}

The data used from this study include six paper geologic maps (shown in Figure 2 and cited in Table 1), and elevation, hydrography and orthoimagery data. The paper maps were digitized by the Missouri Department of Natural Resources, Geological Survey Program and were obtained through the U.S. Geological Survey National Geologic Map Database Portal's link to the Missouri Geologic Survey Map Index (Soller \& Stamm, 2014). Of these six maps, one was published (Weller \& St Clair, 1928). The other five maps were either new geologic surveys (Harrison \& Schultz, 1994; Schultz \& Harrison, 1994) or proposed updates to older surveys (Stewart, Aid, Kidwell, \& Robinson, 1951; James, 1951; Satterfield, 1981) none of which had been rendered into a final map product. The metadata available for the evaluation of the maps were extensive for the published map but sparse for the other five maps. Each map, after downloading, had to be georegistered during which process their Root Mean Squared (RMS) errors were recorded; where necessary, they were also transformed into Universal Transverse Mercator coordinates based upon the 1927 North American Datum.

Data layers on hydrography, elevation and orthoimagery were downloaded from the U.S. Geological Survey web site that contains The National Map viewer (Dollison, 2010). The area downloaded consisted of sufficient border area (more than four times the RMS error) to preclude any anomalous edge effects. 


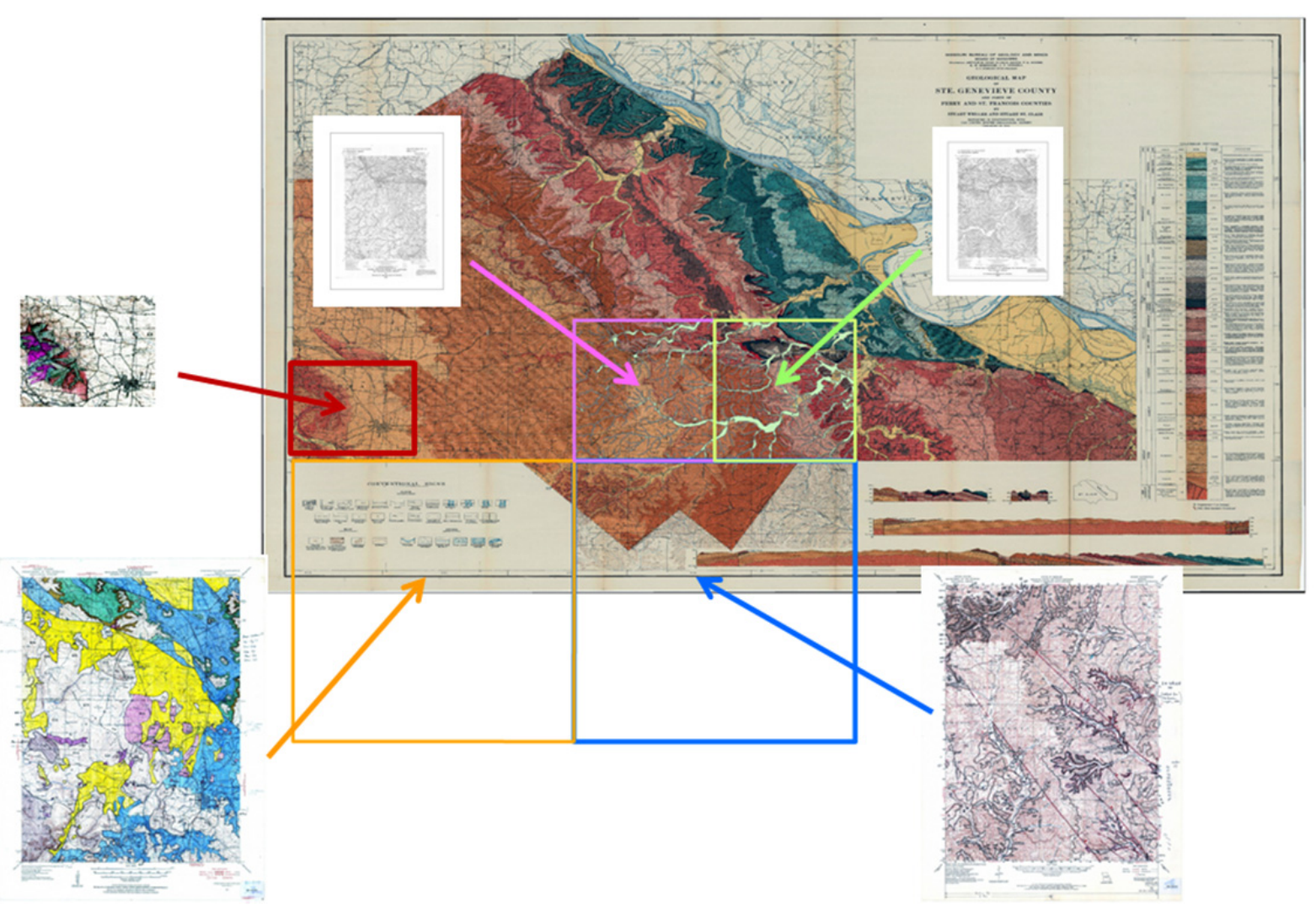

Figure 2. Maps used in the study and their relative locations with respect to the Ste. Genevieve County geologic map. Inset maps include: red box, a portion of the Farmington 15' Quadrangle; pink box, Coffman $71 / 2$ ' Quarangle; green box, Minnith 7 1/2' Quadrangle; blue box, Higdon 15' Quadrangle; and orange box, Fredericktown 15' Quadrangle

Table 1. List of data

\begin{tabular}{llll}
\hline Data Type & Areal Coverage & Year & Source \\
\hline Geologic Map & Ste Genevieve County & 1928 & Weller \& St Clair \\
Geologic Map & Fredericktown 15 minute Quadrangle & 1951 & Stewart \& Aid, revised by Kidwell \& Robinson \\
Geologic Map & Farmington 15 minute Quadrangle & 1951 & James \\
Geologic Map & Higdon 15 minute Quadrangle & 1981 & Satterfield \\
Geologic Map & Coffman 7.5 minute Quadrangle & 1994 & Harrison \& Schultz \\
Geologic Map & Minnith 7.5 minute Quadrangle & 1994 & Schultz \& Harrison \\
Elevation Grid & All & 2002 & Gesch et al. \\
Hydrography & All & 2009 & Simley \& Carswell \\
\hline
\end{tabular}

\section{Method}

\subsection{Geologic Map Uncertainties}

In this paper, the term 'cartographic uncertainty' is applied to that uncertainty which is entirely related to map properties that can be completely defined at the point of use. These properties include georeferencing, line resolution, and pixel size. The cartographic uncertainty is independent from uncertainties inherent with the field data, such as the geographic uncertainty, associated with ascertaining the location of a feature on the surface of the earth, or the geologic uncertainties, associated with the correct identification, measurement, and extension of the feature. These later two uncertainties can only be recorded during the generation of the map data. In a perfect world, these uncertainties would be reflected with the metadata of the digital map, but typically for an archived map, they are not. The cartographic uncertainties described in this study can be tabulated by the user of the maps without relying on how the generating map data were obtained. As the cartographic uncertainties represent only a small part of the total uncertainty, they do not truly reflect the uncertainty of the geologic map, but they do 
provide a useful tool for the conflation of several geologic maps and their integration with different data sets. The cartographic uncertainty used here is a linear combination of the georeferenced uncertainty and the feature location uncertainty.

\subsection{Georeferencing}

Many archived geologic maps have been digitized, usually without any metadata available on the process. Some of these maps are stored in databases linked to the internet (for example, Soller \& Stamm, 2014), while others remain in books, theses, dissertations, or personal files that are far less easy to access. In any case, it will be necessary to geo-register these files. For maps based on USGS topographic quadrangles, the geo-registration can be based upon at least the16 standard fiducial points. Other maps may have fewer, but in either case, the RMS errors to these fiducial points during this registration are saved. Unless there is reason to suspect non-randomness of the RMS errors, they may be considered as coming from a Gaussian distribution and, therefore, confidence limits may be determined from these data (Table 2).

Table 2. Cartographic Uncertainty parameters for each map

\begin{tabular}{lccccc}
\hline \multicolumn{1}{c}{ Map } & Scale & $\begin{array}{c}\text { Root Mean } \\
\text { Square Error } \\
(\mathbf{m})\end{array}$ & $\begin{array}{c}\text { 95\% Confidence } \\
\text { Limit (m) }\end{array}$ & $\begin{array}{c}\text { Line } \\
\text { Thick-ness } \\
(\mathbf{m})\end{array}$ & $\begin{array}{c}\text { Cartographic } \\
\text { Uncertainty (m) }\end{array}$ \\
\hline Coffman & $1: 24000$ & 11.1 & 21.8 & 12 & 24.9 \\
Minnith & $1: 24000$ & 13.3 & 26.1 & 12 & 28.7 \\
Higdon & $1: 42500$ & 17.8 & 34.9 & 30 & 46.0 \\
Fredricktown & $1: 42500$ & 22.2 & 43.6 & 30 & 52.9 \\
Farmington & $1: 42500$ & 17.8 & 34.9 & 30 & 46.0 \\
Ste. Genevieve & $1: 62500$ & 33.3 & 65.4 & 20 & 68.3 \\
County & & & & & \\
\hline
\end{tabular}

The part of the cartographic uncertainty associated with the registration of any two maps can then be obtained by adding the RMS errors from each map in quadrature (as the errors associated with each map are assumed to be independent of the others). The correct relation between the two maps would then have a $95 \%$ probability of occurring within this space (Table 2).

\subsection{Linear features and Scale}

Geologic contacts and faults as projected onto the surface of the Earth are essentially lines. As such, these one-dimensional features are unaffected by map scale. The depiction of these lines by pen-mark, however, does have width, and this width, in meters, is scale dependent. For this study we consider the width of the contact depiction on each map as an essential cartographic uncertainty (measuring only the ambiguity in the contact positioning on the map, and saying nothing about the uncertainty of the actual location of the contact in the field). This uncertainty is combined with the geo-registration uncertainty to give a radius of cartographic uncertainty which also incorporates scale changes between maps.

\subsection{Cartographic Uncertainty}

The total cartographic uncertainty then will be the summation (again, in quadrature, as the two uncertainty measures are linearly independent of each other) of the geo-registration uncertainty with the scale-dependent feature depiction uncertainty. It is this total cartographic uncertainty that will be used to constrain the models of integration and conflation of the various geologic maps and digital databases (Table 2).

Once these uncertainty regions have been mapped out, a target map can be translated throughout the uncertainty region to gain the best fit to the base map based on any number of misfit criteria. For the conflation of the different geologic maps, this simply constitutes an edge or body matching algorithm.

\subsection{Conflation and Integration Procedure}

For the integration of the geologic maps with a database (for example, one of the layers of the U.S. Geological Survey's The National Map), the maps are translated throughout the uncertainty space and misfit is measure based on a given misfit criteria. These criteria might include lithological mapping of limestone boundaries to cliff breaks in the elevation layer, stream lengths in the hydrologic layer contained within Quaternary alluvium markers, glacial ridges and cirques with topographic layers, and so forth. For this region, which exhibits low rolling hill topography (total relief $=360.7 \mathrm{~m}$ ), and a dendritic drainage pattern, the hydrographic layer from The 
National Map was chosen as the integration interface with the Quaternary alluvium units from the geologic maps. The step-by-step procedure that was used for the conflation and integration is given below.

\section{1) All maps are geo-registered based upon at least 16 points}

Note: Registration is based upon linear interpolation, other methods such as Rubber Sheeting are usually continued until the registration points to control points fit is perfect (Rosen \& Saalfeld, 1985) and, as a result, inference on registration uncertainty is lost.

2) RMS misfit map registration is recorded (in meters).

3) All maps are projected into the same coordinate system (if necessary)

4) Width of contact lines are measured (in meters)

Note: This will be scale dependent, and makes no statement on the accuracy or uncertainty in the placement of the line only the uncertainty represented in the actual line itself.

5) For each map a cartographic uncertainty is calculated by combining contact line width with $95 \%$ registration confidence limit (assuming the misfit is random) in quadrature.

Cartographic Uncertainty $(\mathrm{CU})=\left[(1.96 * \text { RMS misfit })^{2}+(\text { contact line width })^{2}\right]^{1 / 2}$

6) Total cartographic uncertainty is the combination in quadrature of uncertainties of any of the maps being conflated (in this example maps were conflated in sequence starting with the most recent map, as a result, only two cartographic uncertainties were combined in any give conflation).

Total Cartographic Uncertainty $=\left[\left(\mathrm{CU}_{\text {Map1 }}\right)^{2}+\left(\mathrm{CU}_{\text {Map2 } 2}\right)^{2}+\left(\mathrm{CU}_{\text {Map3 } 3}\right)^{2}+\ldots\right]^{1 / 2}$

7) Total cartographic uncertainty is then used as the radius of the uncertainty space (a gridded circle about which map translation is allowed in order to minimize contact misfit for conflation and hydrography misfit for integration).

8) One map is chosen as the target to be translated to each of the uncertainty grid points. The sum of the misfit of each edge point (for edge fitting) or body point (for map overlays) is calculated (Figure 3).

Note: Fitting (edge or body) requires 1:1 mapping of geologic units, therefore, any name changes or stratigraphic code changes as a function of time must be rectified before this process can proceed.

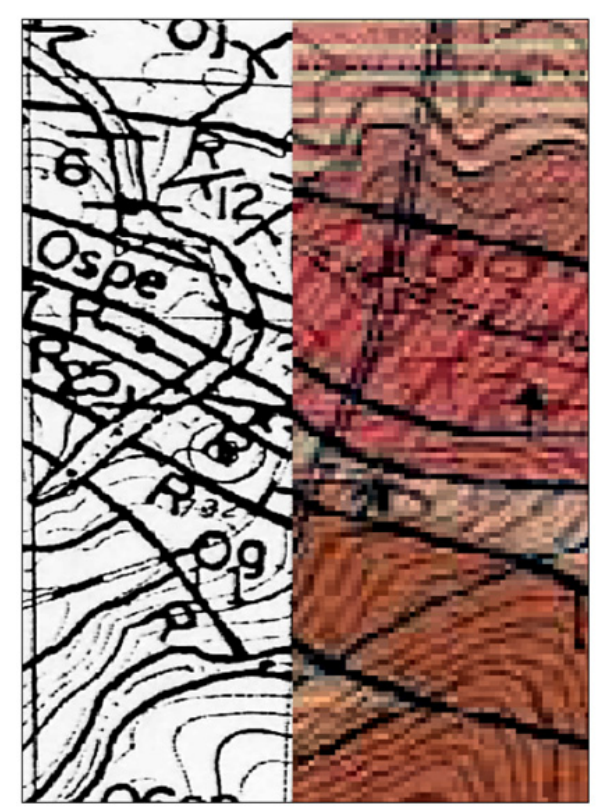

Figure 3. Example of the conflation of two geologic maps. In this case an edge fitting algorithm is used to find the minimum misfit across geologic contacts for these two maps. A similar process is used within the map for overlays

9) Simultaneously, in this study, the length of stream lines from the National Hydrography Dataset (NHD) 
contained within the Quaternary alluvium on the most reliable map (taken as the more recent map unless other evidence presents itself) is calculated at each uncertainty grid point (Figure 4). This is done by translating the origin of the alluvium to each point on the uncertainty grid (each point dislocation being one lag, which in this case was one meter) and determining misfit, Note: As suggested above, in other regions, different geographic markers might be better as a tie-in (e.g. Mesas, Buttes, Canyons, Hogbacks and possibly even Cuestas in arid environments; horns, drumlins, eskers and moraines could be used in glacial environments; sink holes and disappearing streams in karst; highly erosional resistant beds contacting low erosional resistant beds, or any truly distinctive geologic marker.)

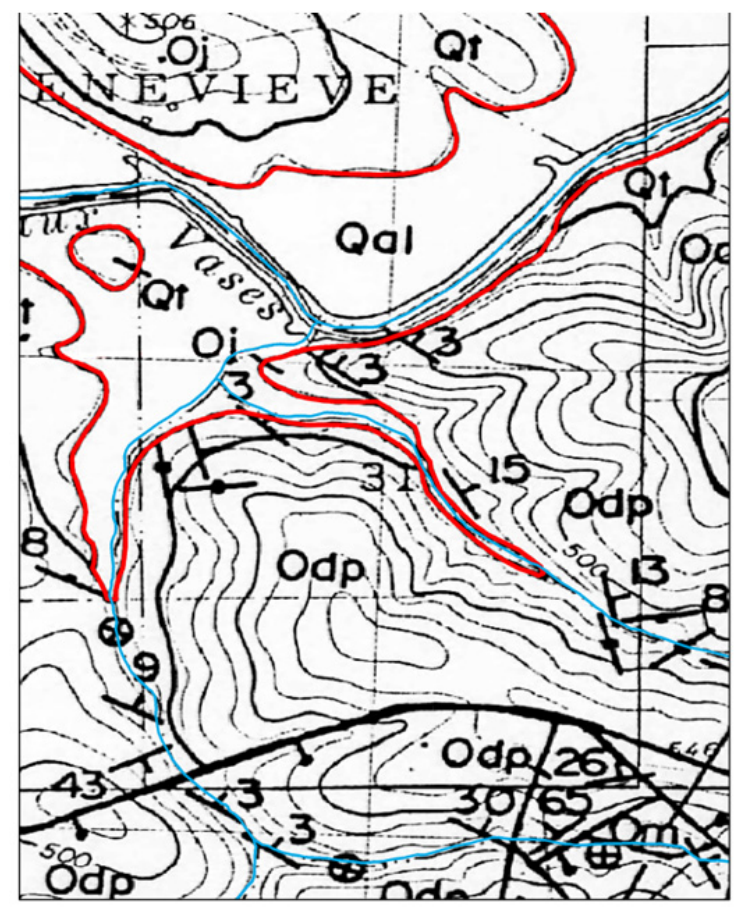

Figure 4. Integration of the NHD stream line data with the geologic map. The length of stream lines that do not fall within the Qal areas is minimized

10) The stream line fit is converted to a misfit by subtracting the streamline length contained within the Quaternary alluvium from the total streamline length in the target area.

11) To avoid either the conflation or integration misfits from dominating the results, both misfits are normalized by the maximum misfit for each (e.g. fractional conflation misfit at grid point $1=$ conflation misfit at grid point 1 in meters divided by maximum conflation misfit over all grid points, in meters).

12) The misfits are summed in quadrature to generate the combined misfit statistic, and the minimum denotes the translation that best matches the maps and The National Map data.

13) Once the maps have been translated to optimal position, remaining misfit is minimized by linear interpolation within the uncertainty region of the conflated map if possible. If the misfit is too large for reasonable accommodation within the uncertainty region, the misfit is left unmapped and noted in the metadata.

\section{Results}

Misfit for the conflation of the geologic maps is measured by the distance between aligning points (the spatial distance between these two points, when minimized, is equivalent to the L1 Norm, which in statistics is the absolute value of the difference between points). For edge-mapping conflation, these points are typically the edge-terminus of geologic formations or fault lines. For body-matching conflation, misfit is measured by the misalignment distance of selected identical points along matching formation boundaries or fault lines. The misfits are summed for each position in the geographical uncertainty space (one-meter spacing) and the minimum misfit location is found (Figure 5). 


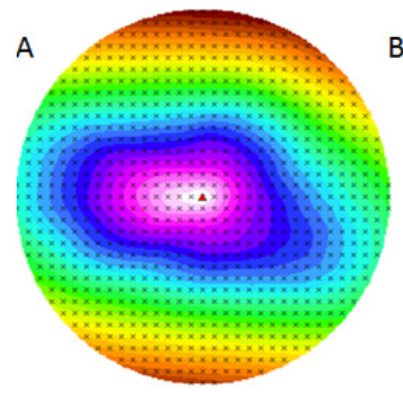

Minnith to Coffman
B

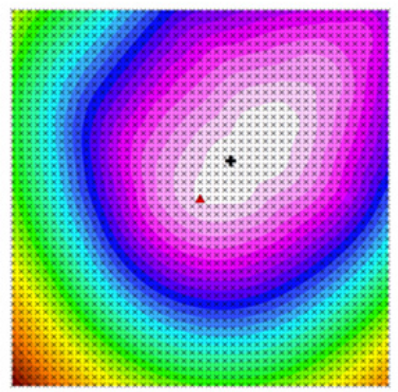

Coffman/Minnith to Higdon

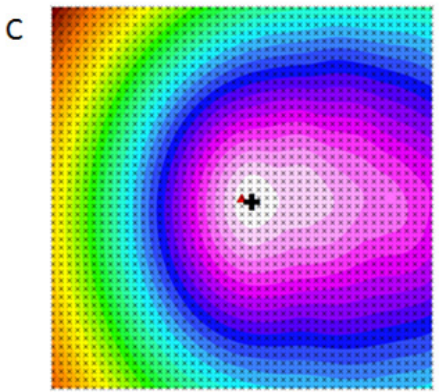

Coffman/Minnith/Higdon to Fredricktown
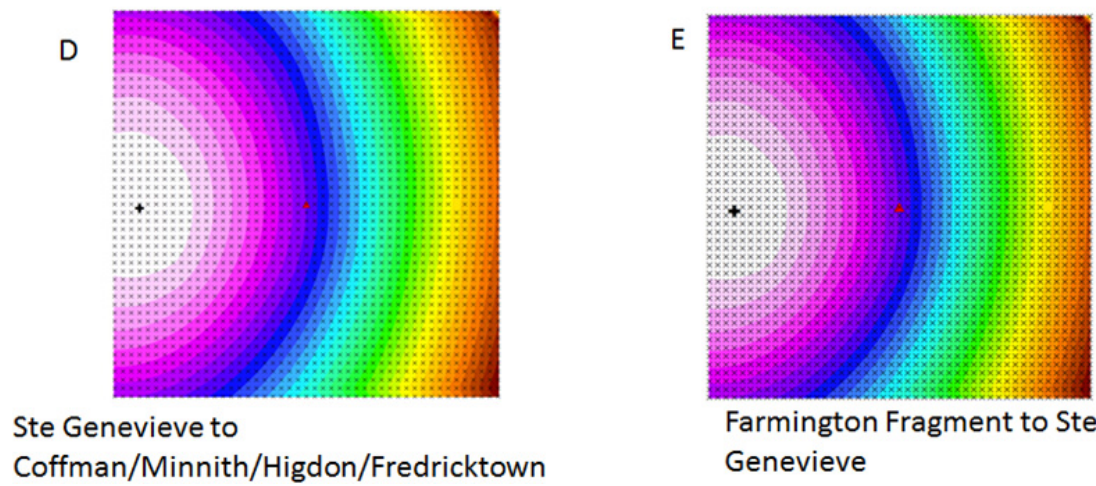

Farmington Fragment to Ste Genevieve

Figure 5. L1-Norm misfits space for each stage of the conflation process. X-marks show 1 meter spacing, red triangles show origin, and black crosses show least misfit locations. Hot colors (red, orange, yellow) show the greater misfit, cold colors (white, magenta, blue) show the lesser misfit

The distance and direction from the origin (representing no movement of the conflating map features, shown by a red triangle in Figure 5) to the minimum misfit position (shown by the black cross in Figure 5) is the amount of translation that all the features in the conflating map undergo. These vectors are shown for each map conflation in Table 3.

Table 3. Conflation parameters that minimize misfit for each map addition.

\begin{tabular}{|c|c|c|c|}
\hline Base Map(s) & Map Conflated & Distance (m) & Direction $(\mathrm{E}$ of $\mathrm{N})$ \\
\hline Coffman & Minnith & 0.3 & $270^{\circ}$ \\
\hline Coffman/Minnith & Higdon & 6.0 & $40^{\circ}$ \\
\hline Coffman/Minnith/Higdon & Fredricktown & 1.2 & $112.4^{\circ}$ \\
\hline Coffman/Minnith/Higdon/Fredricktown & Ste. Genevieve/Farmington & 19.5 & $268.3^{\circ}$ \\
\hline Ste. Genevieve & Farmington & 20.0 & $268.6^{\circ}$ \\
\hline
\end{tabular}

Figure 5 shows a marked asymmetry to the misfit. Such an asymmetry should be expected, in that Figure 5A, $\mathrm{B}, \mathrm{C}$ and $\mathrm{D}$ are edge-joined and Figure $5 \mathrm{E}$ is body-joined. If the conflated map is joined along an eastern or western boundary of the origin map, then the least misfit axis should be aligned in a direction with a significant east-west component (see Figures 5A and 5C), since features aligned in north-south strike would not cross such a boundary. Whereas maps conflated along a northern or southern boundary should show a distinct north-south alignment (Figure 5B). As maps are conjoined about both a north or south boundary and an east or west boundary (Figure 5D) or are body-conflated (Figure 5E), a more symmetrical pattern should be apparent.

Integration misfit is parameterized by how much of the total stream length does not lie upon Quaternary alluvium. While not all streams produced Quaternary alluvium, and some streams may have meandered outside the alluvium mapped in the past, it is assumed that a best fit model is the one that minimizes the length of the stream lines that lie outside this stratum over a large area. The National Map layers are considered to be the data upon which the conflated geologic map features will be integrated. Figure 6 shows the sum of the misfits for a set of lags of the geologic map around the origin. The drainage pattern is dendritic for this region and as a 
result a more random misfit pattern is seen with very little variation shown within 10 meters of the origin. The best fit location is denoted by the large black cross. This is $6 \mathrm{~m}$ east southeast of the origin (Table 4).

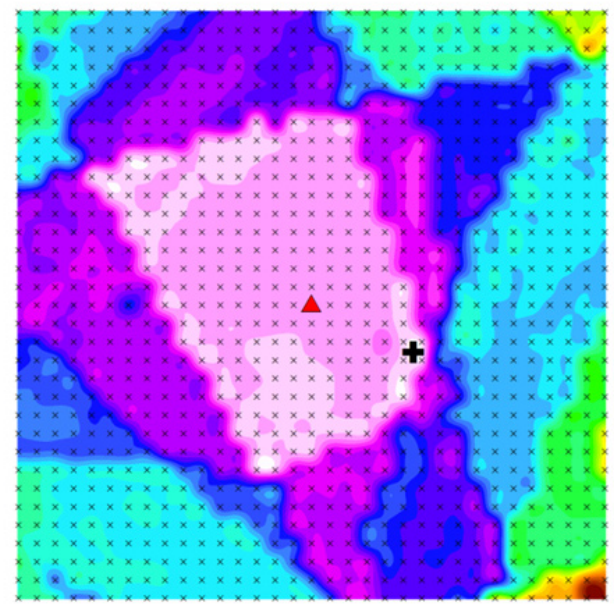

Figure 6. L1 Norm for misfit through uncertainty space of the geologic map integration with hydrography dataset (NHD). X-Marks denote 1-meter spacing. Again, hot colors (red, orange, yellow) show the greater misfit, cold colors (white, magenta, blue) show the lesser misfit

Table 4. Integration parameters that minimize misfit for conflated geologic map with the National Hydrography Datasets (NHD) flowlines

\begin{tabular}{llcc}
\hline Base Feature & Integrated Map & Distance (m) & Direction $\quad$ (E of N) \\
\hline NHD Flowlines & Conflated Geologic Map & 6.0 & $117^{\circ}$ \\
\hline
\end{tabular}

Translating the conflated geologic map through the vector described in Table 4 provides the best fit to the National Hydrography Dataset's (NHD) stream lines. These lines have been extensively integrated with the other The National Map data layers (Usery, Finn, \& Starbuck, 2009; Sugarbaker \& Carswell, 2011) and, as such, the conflated geologic map is integrated with all data layers for The National Map (Figure 7). The NHD

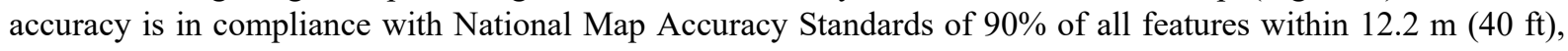
(Simley \& Carswell, 2009).

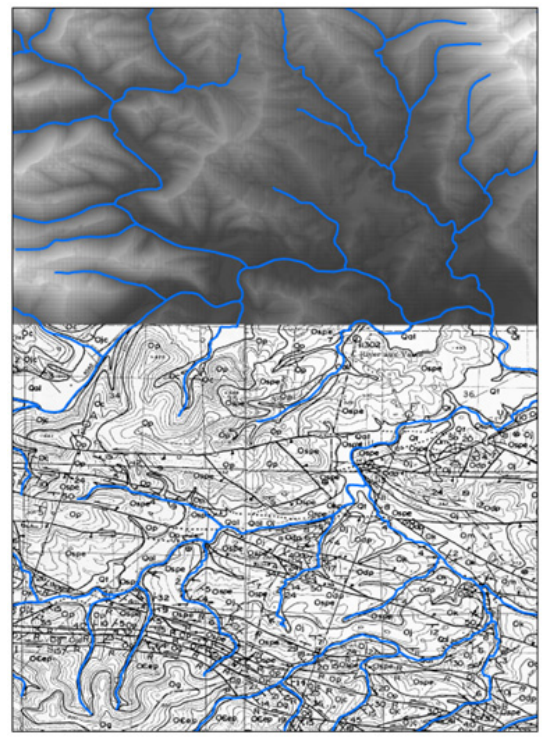

Figure 7. Integration of the conflated geologic map features with the data layers from The National Map. Blue lines show NHD flowlines, shaded region is hillshade version of the Digital Elevation Model (DEM) 
Further, since both conflation misfits and integration misfits were normalized by the maximum misfit of each before summation, no one statistic is seen to dominate. The best fit is seen to involve little or no movement of the maps, implying that the original digitization of the maps was done fairly consistently. A standard chi-squared $\left(\mathrm{c}^{2}\right)$ analysis yielded the $95 \%$ confidence limit show in Figure 8 . This confidence limit is roughly elliptical in shape with a semi-major axis trending WNW to ESE (Table 5) with a semi-major axis of $10.6 \mathrm{~m}$, and a semi-minor axis of $6.8 \mathrm{~m}$, which yields an area of about $226 \mathrm{~m}^{2}$.

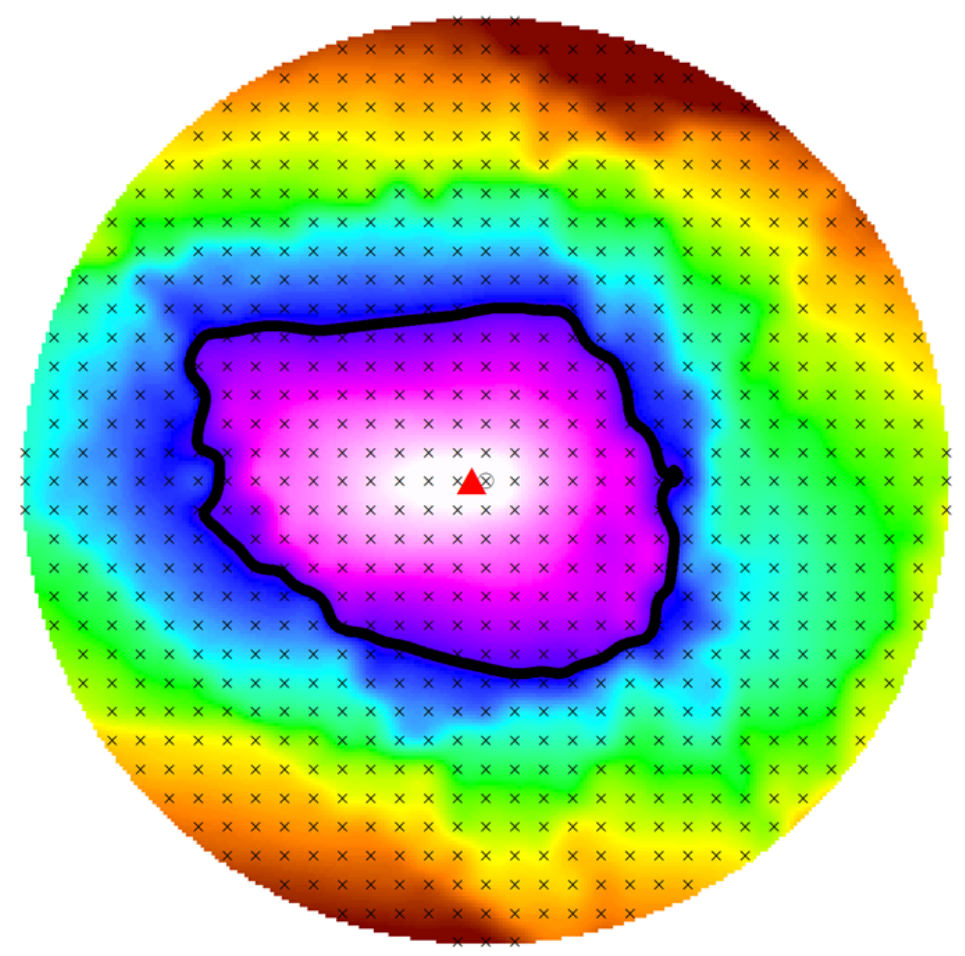

Figure 8. L1 Norm for misfit through uncertainty space of combined conflation and integration statistic, Circle = origin, Red triangle $=$ best fit, Solid black line $=$ chi-squared, 95-percent confidence limit. Crosses show 2-meter spacing

Table 5. Confidence ellipse (95\%) from $\chi^{2}$ - test for both conflation and integration of geologic maps with The National Map data layers

\begin{tabular}{ccccc}
\hline & $\begin{array}{c}\text { Semi-major axis } \\
(\mathbf{m})\end{array}$ & $\begin{array}{c}\text { Semi-minor axis } \\
(\mathbf{m})\end{array}$ & $\begin{array}{c}\text { Azimuth of semi-major } \\
\text { axis (E of N) }\end{array}$ \\
\hline $\begin{array}{c}\text { Combined } \\
\text { Uncertainty }\end{array}$ & $\begin{array}{c}95 \% \text { Confidence } \\
\text { Ellipse }\end{array}$ & 10.6 & 6.8 & $141^{\circ}$ \\
\hline
\end{tabular}

This uncertainty ellipse is the minimum combined uncertainty (as it is associated with the anchor map in the conflation process) and therefore gives the tightest constraint for the integration of additional datasets. The conflated geologic map can now be digitized and the resulting digital dataset overlain on The National Map layers as a fully integrated dataset (Figure 9). 

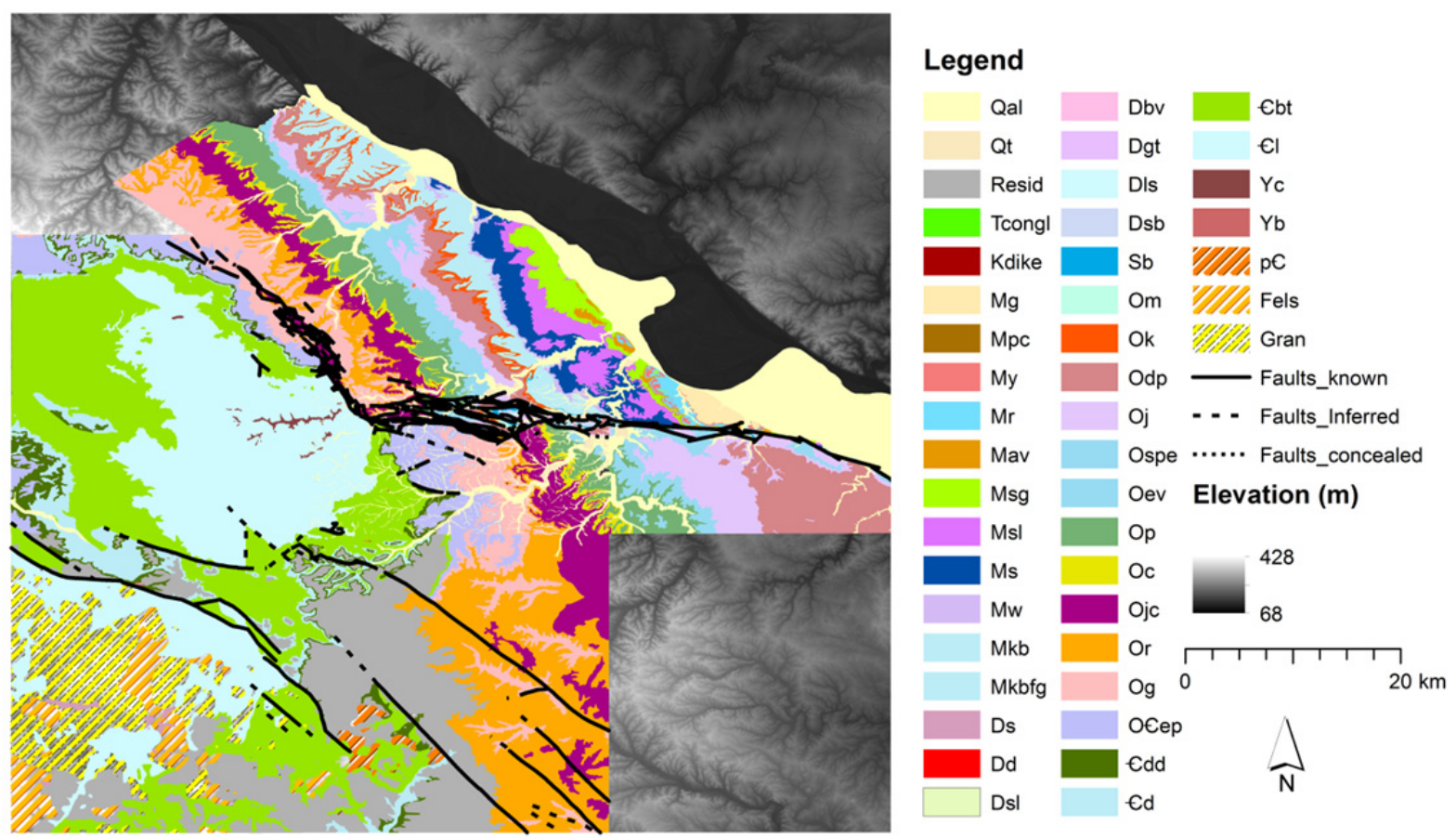

Figure 9. Conflated and integrated digital geologic surface bedrock map for areas of Ste. Genevieve, St Francois and Perry counties in SE Missouri. The geologic maps have been conflated to give a larger areal content than each of the individual maps and have been integrated with the NHD of The National Map of the U.S. Geological Survey. The NHD is also integrated with the NED data (shown in Figure 7), as well as layers on orthoimagery,

land use, transportation, structures, and geologic names. Associatively, the digital geographic map is also integrated with these layers

\section{Discussion}

The division of the uncertainties associated with geologic map usage into three categories (cartographic, geographic and geological) allows for the distinction between uncertainties associated with plotting and storage (cartographic), those associated with location in the field (geographic), and those associated with measurements and interpretation (geological). The cartographic uncertainty, while useful for conflation and integration purposes, will typically be minor compared with non-GPS based geographic uncertainties (Clegg et al., 2006; Whitmeyer, Nicoletti, \& De Paor, 2010), particularly when field notes are not associated with the metadata, and the measuring and interpretive geological uncertainties.

The latter of these (the geological uncertainties) are likely to be the largest, particularly when subsurface models are codified. Trying to constrain these uncertainties is a topic of active research with the most prominent methods involving:

- Perturbation methods where the uncertainty is derived from end-members of multiple possible model simulations (e.g., Lindsay, Aillère, Jessell, de Kemp \& Betts, 2012; Lindsay, Aillère, Jessell, de Kemp \& Betts, 2013; )

- Withholding a subset of geologic data from the model construction which is used afterwards to quantify model accuracy (e.g., Sturkell, Hokobsson, \& Gyllencreutz, 2008)

- Building stochastic models and other statistical approaches (e.g., López-Vázquez, 2012; Wellman, Horowitz, Schill \& Regenauer-Lieb,, 2010; Wellman \& Regenauer-Lieb, 2012; Leung, Goodchild \& Lin, 1993)

- Using expert analyses to estimate model uncertainty (e.g., Lark et al., 2013; Lark, Mathers, Marchant, \& Hulbert, 2014)

- Using geophysical data to constrain geologic model uncertainty (e.g., Jessell, Aillères, \& de Kemp, 2012; Joly, Martelet, Chen, \& Faure, 2008)

The common thread through these methods is the importance of understanding the uncertainties inherent in the 
use of geologic map and models. This becomes paramount in the digital age as any user has the ability to call up a map or model designation down to the meter level on any of an assorted variety of electronic devises. While geologists have long known the interpretative and scale dependent nature of geologic maps, this knowledge may be lacking for varied uses by developers, planners, or home owners.

The uncertainty associated with any feature on a geologic map must then be a function of the cartographic, geographic and geologic uncertainties. In general, these are from independent sources of error and, as such, can be combined in quadrature.

Combined uncertainty $=\left[(\text { cartographic uncertainty })^{2}+(\text { geographic uncertainty })^{2}+(\text { geologic uncertainty })^{2}\right]^{1 / 2}$

Once uncertainties have been established, there remains the question of how best to represent these in a digital database. Again several methods have been suggested including the inclusion of statistical parameters in the data (Kennelly, 2002), presenting pixel size (or in the case of a three-dimensional model, the volume element ('voxel', Lindsay et al., 2013) size), or simply not presenting an image when the image representation drops below the uncertainty. In any case, it is important to relate the uncertainty in the model to the potential user.

The $95 \%$ confidence limit for the combined conflation and integration process (as given in Table 5) used here has the added value of providing the basis for further data integration associated with this particular map. This confidence ellipse represents the uncertainty space through which additional data sets can be translated in order to achieve a best fit with the host data. The utility of integrating survey data to a base such as The National Map layers has been previously demonstrated in general by Shoberg, Stoddard, \& Finn (2013), for gravity surveys in particular by Shoberg \& Stoddard (2014), and for disaster restoration modeling by Ramachandran, Long, Shoberg, Corns, \& Carlo, (2015; 2016).

\section{Conclusions}

Using cartographic uncertainties derived from six digitized archive geologic maps as constraints, these maps were conflated with each other and integrated with The National Map data sets for parts of Ste. Genevieve, St. Francois, and Perry counties in southeastern Missouri. Analysis of the conflation and integration process yields a $95 \%$ confidence interval that is useful for further data integration efforts.

This confidence interval, based upon cartographic uncertainties alone, suggests the position of any particular geologic feature on the combined map can be located with $95 \%$ confidence within an area of $226 \mathrm{~m}^{2}$.

This uncertainty does not incorporate positional uncertainties due to the field work or geologic measurements or interpretations. Nor does it assume that field errors are greater or less than cartographic errors, merely that it is difficult to quantify these errors by a third party, even if the literature describing outcrop locations exists. However, there is considerable work in progress to quantify these other sources of uncertainty, the representation of which will become increasingly important as more and more digital geologic maps and models become available to all users (Goodchild, Lin, \& Leung, 1994).

Given the parameters by which the cartographic uncertainties were constructed, it is safe to say that the conflation and integration process described here does not improve the accuracy of any geologic interpretation from these maps. What they do provide, however, is a self-consistent method that limits additional degradation of this accuracy while at the same time yielding the valuable addition of both wider geologic map coverage and other diverse data sets.

\section{Acknowledgements}

The author would like to thank Dr. Paul Stoddard, Northern Illinois University, Dr. Klaus J. Schulz, U.S. Geological Survey and Mike Finn, U.S. Geological Survey for their thoughtful and helpful comments on this manuscript.

\section{References}

Clegg, P., Bruchiatelli, L., Domingos, F., Joines, R. R., De Donates, M., \& Wilson, R. W. (2006). Digital geological mapping with tablet PC and PDA: A Comparison, Computers and Geosciences, 32, 1682-1698. http://dx.doi.org/10.1016/j.cageo.2006.03.007

Dollison, R. M. (2010). The National Map: New viewer, services, and data download: U.S. Geological Survey Fact Sheet 2010-3055, p2. Retrieved from http://pubs.usgs.gov/fs/2010/3055/

Gesch, D., Oimen, M., Greenlee, S., Nelson, C., Stueck, M., \& Tyler, D. (2002). The National Elevation Dataset, Photogrammetric Engineering and Remote Sensing, V(6)8, 5-11.

Goodchild, M. F., Lin, C. C., \& Leung, Y. (1994). Visualizing Fuzzy Maps, In H.H. Hearnshaw, \& D. J. Unwin 
(Eds.), Visualization in GIS, Wiley, New York, NY, 158-167.

Harrison, R. W., \& Schultz, A. (1994). Geologic map of the Coffman 7.5 min. quadrangle, Ste. Genevieve County, Missouri: U.S. Geological Survey, Open-File Report OF-94-419, scale 1:24,000

Hatcher, R. D. J. (2005). Non-survey, non-digital completed geologic maps in file drawers and theses: How can they be transformed into useful, available, digital, geospatial data? In D. P. Soller, (Ed.), Digital Mapping Techniques '05 - Workshop Proceedings, U.S. Geological Survey, Open-File Report, 2005-1428, p 11-21.

James, J. A. (1951), Field map of the Farmington 15' quadrangle, Missouri: Missouri Department of Natural Resources, Division of Geology and Land Survey, scale 1: 62, 500.

Jessell, M.W., Aillères, L., \& de Kemp, E. A. (2012). Towards an integrated inversion of geoscientific data: What price of geology? Tectonophysics, 490, 294-306. http://dx.doi.org/10.1016/j.tecto.2010.05.020

Joly, A., Martelet, G., Chen, Y., \& Faure, M. (2008). A multidisciplinary study of a syntectonic pluton close to a major lithospheric fault - Relationships between Montmarault granitic massif and the Sillon Houiller Fault in the Variscan French Massif Central: 2. Gravity, aeromagnetic investigations and 3-D geologic modeling, Journal of Geophysical Research, 113, B01404. http://dx.doi.org/10.1029/2006JB004744

Kennelly, P. J. (2002). Visualizing the uncertainty of geologic maps, in Soller, D. P., Digital Mapping Techniques '02 - Workshop Proceedings, U.S. Geological Survey. Open-File Report, 2(370), 181-187.

Lark, R. M., Mathers, S. J., Marchant, A., \& Hulbert, A. (2014). An index to represent lateral variation of the confidence of experts in a 3-D geological model, Proceedings of the Geologists' Association, 125, 267-278. http://dx.doi.org/10.1016/pgeola.2015.05.002

Lark, R. M., Mathers, S. J., Thorpe, S., Arkely, S. L. B., Morgan, D. J., \& Lawrence, D. J. D. (2013). A statistical assessment of the uncertainty in a 3-D geological framework model. Proceedings of the Geologists Association, 124, 946-958. http://dx.doi.org/10.1016/pgeola.2013.01.005

Leung, Y., Goodchild, M. F., \& Lin, C. C. (1993). Fuzzy Scenes and Probability Fields, In H. J. Newton (Ed.)., Computing Sciences and Statistics, 24. Graphics and Visualization (Proceedings of the $24^{\text {th }}$ Symposium on Interface), Fairfax Station, VA, Interface Foundation of North America, 416-422

Lindsay, M. D., Aillères, L., Jessell, M. W., de Kemp, E. A., \& Betts, P. G. (2012). Locating and quantifying geological uncertainty in three-dimensional models: Analysis of the Gippsland Basin, southeastern Australia, Tectonophysics, 10(27), 546-547. http://dx.doi.org/10.1016/j.tecto.2012.04.007

Lindsay, M. D., Jessell, M. W., Aillères, L., Perrouty, S., de Kemp, E. A., \& Betts, P. G. (2013). Geodiversity: Exploration of 3D geological model space, Tectonophysics, 594, 27-37. http://dx.doi.org/10.1016/j.tecto.2013.03.0013

López-Vázquez, C. (2012). Positional accuracy improvement using empirical analytic functions, Cartography and Geographic Information Science (CaGIS), 39, 133-139. http://dx.doi.org/10.1559/15230406393133

Ramachandran, V., Long, S. K., Shoberg, T., Corns, S., \& Carlo, H. (2015). Modeling supply chain network resiliency in the aftermath of an extreme event, Natural Hazards Review, 16(4), 040150015. http://dx.doi.org/10.1061/(ASCE)NH.1527-6996.0000184.

Ramachandran, V., Long, S., Shoberg, T., Corns, S., \& Carlo, H. (2016). Post-Disaster Supply Chain Interdependent Critical Infrastructure System Restoration: A Review of Data Necessary and Available for Modeling. Data Science Journal, 15(1), 1-13. http://dx.doi.org/10.5334/dsj-2016-001.

Rosen, B., \& Saalfeld, A. (1985). Match Criteria for Automated Alignment, In: Proceedings of the $7^{\text {th }}$ International Symposium on Computer Assisted Cartography (AutoCarto 7), 456-462.

Satterfield, I. R. (1981). Geologic map of the Higdon 15' quadrangle, Missouri: Missouri Department of Natural Resources. Division of Geology and Land Survey, scale 1(62), 500.

Schultz, A., \& Harrison, R. W. (1994). Geologic map of the Minnith 7.5 min. quadrangle, Ste. Genevieve and Perry Counties, Missouri: U.S. Geological Survey, Open-File Report OF-94-421, 1(24),000.

Shoberg, T., \& Stoddard. P. R. (2013). Integrating stations from the North America Gravity Database into a local GPS-based land gravity survey. Journal of Applied Physics, 89, 76-83. http://dx.doi.org/10.1016/j.japgeo.2012.11.011

Shoberg, T., Stoddard, P. R., \& Finn, M. P. (2012). Rejuvenating pre-GPS Era Geophysical Surveys with The $\begin{array}{llllll}\text { National Map. Journal of Surveying Engineering, } & \text { 138, }\end{array}$ 
http://dx.doi.org/10.1061/(ASCE)SU.1943-5428.0000068.

Simley, J.D., \& Carswell Jr., W.J. (2009). The National Map-Hydrography: U.S. Geological Survey Fact Sheet 2009-3054, 4.

Soller, D. R., \& Stamm, N. R. (2014). The National Geologic Map Database Project - 2010 and 2011 Report of Progress, In D. P. Soller (Ed.), Digital Mapping Techniques '11-12 Workshop Proceedings: U.S. Geological Survey Open-File Report 2014-1167, 134. http://dx.doi.org/10.3133/ofr20141167

Soller, D. R., Berg, T. M., \& Wahl, R. (2000). Developing the National Geologic Map Database, Phase 3 - An Online, "Living" Database of Map Information, In D. P. Soller (Ed.). Digital Mapping Techniques '00 Workshop Proceedings, U.S. Geological Survey Open-File Report 00-325. http://pubs.usgs.gov/openfile/of00-325/soller4.html

Stewart, D. R, Aid, K., Kidwell, A. L., \& Robinson, F. S. (1951). Geologic map of the Fredericktown 15' quadrangle, Missouri: Missouri Department of Natural Resources, Division of Geology and Land Survey, scale 1:48,000.

Sturkell, E., Hakobsson, M., \& Gyllencreutz, R. (2008). How True are Geological Maps? An Exercise in Geological Mapping, Journal of Geoscience Education, 56, 297 - 301.

Sugarbaker, L. J., \& Carswell, Jr. W. J. (2011). The National Map. U.S. Geological Survey Fact Sheet, 20113042.

Usery, E. L., Finn, M. P., \& Starbuck, M. (2009). Data Layer Integration for The National Map of the United States, Cartographic Perspectives, 62, 38-41.

Weller, S., \& St. Clair, S. (1928). Geology of Ste Genevieve County, Missouri, Bureau of Mines Publications Series 2, Number 22, Missouri Bureau of Geology and Mines, Rolla, MO, 352 pp.

Wellman, J. F., \& Regenauer-Lieb, K. (2012). Uncertainties have a meaning: Information entropy as a quality measure of 3-D geological models, Tectonophysics, 526-529, 207-216. http://dx.doi.org/10.1016/j.tecto.2011.05.001

Wellman, J. F., Horowitz, F., Schill, E., \& Regenauer-Lieb, K. (2010). Towards incorporating uncertainty in structural data in 3-D geologic inversion, Tectonophysics, 490, 141-151. http://dx.doi.org/10.1016/j.tecto.2010.04.022

Whitmeyer, S. J., Nicoletti, J., \& De Paor, D. G. (2010). The digital revolution in geologic mapping, GSA Today, 20, 4/5, 4 - 10. http://dx.doi.org/10.1130/GSATG70A.1

Wunderlich, A. L., \& Hatcher, R. D. Jr. (2009). Rescuing Legacy Digital Data: Maps Stored in Adobe IllustratorTM Format, In D. H. Soller (Ed.). Digital Mapping Techniques '08 - Workshop Proceedings, U.S. Geological Survey Open-File Report, 2009-1298, 85-100. https://pubs.usgs.gov/of/2009/1298

\section{Copyrights}

Copyright for this article is retained by the author(s), with first publication rights granted to the journal.

This is an open-access article distributed under the terms and conditions of the Creative Commons Attribution license (http://creativecommons.org/licenses/by/3.0/). 